\title{
Reconciling Primary Care and Specialist Perspectives on Prostate Cancer Screening
}

\author{
Richard M. Hoffman, MD, MPH \\ Michael J. Barry, $M D^{2}$ \\ Richard G. Roberts, MD, JD \\ Harold C. Sox, MD \\ 'Medicine Service, Albuquerque VA Medi- \\ cal Center, Departments of Medicine and \\ Family and Community Medicine, Univer- \\ sity of New Mexico School of Medicine, \\ Albuquerque, New Mexico
}

${ }^{2}$ Harvard Medical School, Boston,

Massachusetts

${ }^{3}$ Department of Family Medicine, University of Wisconsin School of Medicine and Public Health, Madison, Wisconsin

${ }^{4}$ The Dartmouth Institute, Dartmouth Medical School, Hanover, New Hampshire

Conflicts of interest: Dr Hoffman reports receiving an honorarium for authoring the prostate cancer screening chapter in UpToDate, payment for providing expert testimony regarding prostate cancer screening, National Institutes of Health grant funding to evaluate prostate cancer screening in the elderly, and partial salary support for medical editing from Informed Medical Decisions Foundation, a not-for-profit 501(c)3 private foundation. Dr Barry receives salary support as president of the Informed Medical Decisions Foundation. The Foundation develops content for patient education programs, including programs on prostate cancer screening and treatment. The Foundation bas an arrangement with a for-profit company, Health Dialog, to coproduce these programs. The programs are used as part of the decision support and disease management services Health Dialog provides to consumers through bealth care organizations and employers. Dr Roberts reports no conflicts. Dr Sox reports no conflicts.

\section{CORRESPONDING AUTHOR}

Richard M. Hoffman, MD, MPH

Mailstop 111

1501 San Pedro Dr SE

Albuquerque, NM 87108

rhoffman@unm.edu

\begin{abstract}
When specialists propose screening guidelines for primary care clinicians to implement, differences in perspectives between the 2 groups can create conflicts. Two recent specialty organization guidelines illustrate this issue. The American Urological Association guideline panel and National Comprehensive Cancer Network recommend that average-risk men first be counseled about the risks and benefits of prostate-specific antigen screening for prostate cancer at age 40 rather than at the previously recommended age of 50 years. There is no direct evidence, however, that this recommendation has any impact on prostate cancer-specific mortality. To avoid distracting primary care clinicians from providing services with proven benefit and value for patients, professional organizations should follow appropriate standards for developing guidelines. Primary care societies and health care systems should also be encouraged to evaluate the evidence and decide whether implementing the recommendations are feasible and appropriate.
\end{abstract}

Ann Fam Med 2012;10:568-571. doi:10.1370/afm.1399.

Ob, East is East, and West is West, and never the twain shall meet.

Rudyard Kipling, The Ballad of East and West

\section{PRIMARY CARE VS SPECIALIST PERSPECTIVES ON CANCER SCREENING}

hould primary care clinicians adopt guidelines developed primarily by specialists? We believe the answer should depend on the quality $\checkmark$ of the evidence and the appropriateness and feasibility of implementing the guideline. Compared with primary care clinicians, specialists care for disproportionate numbers of patients with advanced-stage disease. Both groups of physicians have the same goals of minimizing morbidity and mortality from the diseases that they treat, but specialists are not under the same obligation to weigh priorities across all diseases. These different perspectives can create conflict when specialists propose screening guidelines. We illustrate this conflict with the case of prostate cancer screening in younger men.

\section{Rationale for Screening at an Earlier Age}

Owing to inconclusive evidence, past prostate cancer screening guidelines from specialist physicians have differed sharply from those of generalist clinicians. ${ }^{1-3}$ By applying better evidence, screening recommendations have converged toward a consensus that men should be informed of the benefits and harms of screening. Now, however, 2 prominent specialty groups have issued guidelines that adhere to the spirit of informed decision making, but have extended the recommendations to younger men. 
These guidelines illustrate the consequences of conflicting perspectives.

In 2009, the American Urological Association (AUA) released a guideline on prostate-specific antigen (PSA) screening for prostate cancer. ${ }^{4}$ The guideline, developed by a multidisciplinary panel largely composed of specialists, departed from the previous recommendation to begin addressing screening with average-risk men at age 50 years, stating that "... the age for obtaining a baseline PSA test [in a wellinformed patient] has been lowered to 40 years." The National Comprehensive Cancer Network (NCCN), which convened a multidisciplinary panel dominated by specialists, also recommended offering average-risk men baseline PSA testing at age 40 years. ${ }^{5}$

The AUA and NCCN guidelines are intended for health care professionals who counsel patients about screening. Because most people receive preventive services in the primary care setting, the responsibility for implementing these guidelines will fall largely to primary care clinicians. Explaining the benefits and harms of PSA screening entails a potentially time consuming discussion, but often this type of discussion does not take place. ${ }^{6-8}$ The US Preventive Services Task Force (USPSTF) currently recommends delivering 35 adult preventive services, for which it found high certainty of moderate or high net benefit. ${ }^{9}$ Investigators have estimated that it would require 7.4 hours a day for primary care physicians to provide these recommended services. ${ }^{10}$ Given the limited time in a typically rushed primary care visit, is there sufficient evidence that the net benefits of starting PSA screening at age 40 years justify additional counseling time?

\section{Evidence for Screening at an Earlier Age}

The most recent AUA and NCCN guidelines were released after the 2009 publication of 2 large randomized screening trials, the US Prostate, Lung, Colorectal, and Ovarian Cancer Screening Trial (PLCO) ${ }^{11}$ and the European Randomized Study of Screening for Prostate Cancer (ERSPC). ${ }^{12}$ In the PLCO, which enrolled men aged 50 to 74 years, screening did not reduce prostate cancer mortality, though screening was widespread among the control group. ${ }^{11}$ The ERSPC, which had less contamination, reported that screening significantly reduced prostate cancer mortality by $20 \%$ among men aged 55 to 69 years. ${ }^{12}$ The absolute mortality risk reduction with screening, however, was less than 1 per 1,000 men, implying that more than 1,400 men needed to be screened to prevent 1 prostate cancer death in 9 years of follow-up. The small mortality reduction with screening must be weighed against its potential harms, including false-positive tests, overdiagnosis, and treatment complications. ${ }^{13}$
What do the epidemiology of prostate cancer and these results say about the wisdom of extending PSA screening to men aged 40 years? Of 29,093 US prostate cancer deaths in 2007 , nearly $96 \%$ occurred among men aged 60 years and older; only about 100 deaths (and just under $3 \%$ of incident cases) occurred in men aged 50 years and younger. ${ }^{14}$ Although we lack direct evidence that a baseline PSA at age 40 years reduces the mortality toll after age 60 years, the ERSPC provides hints to the contrary. While not included in the estimate of screening efficacy, men aged between 50 and 54 years were randomized in the ERSPC. After about 55,000 personyears of follow-up, only 6 prostate cancer deaths had occurred in the screening group and 4 in the control group. ${ }^{12}$ A decision model study based on ERSPC and population data suggested that the lifetime benefit of beginning routine screening for average-risk men at age 40 rather than age 50 years would be less than 1 fewer prostate-cancer deaths per 1,000 men. ${ }^{15}$

The remaining arguments for discussing earlier screening rely on weak indirect evidence. The NCCN made a category $2 \mathrm{~B}$ recommendation (nonuniform consensus based on "lower-level evidence") based on the rationale that first offering PSA testing at the age of 40 years could prevent "tragic, untimely early deaths."5 The AUA guideline speculated that being diagnosed in their 40s might cure some additional men destined to die at age 55 to 64 years. ${ }^{4}$ They reasoned that these younger men might have more "curable" cancer than older men based on observational data showing more favorable tumor characteristics and lower risk for PSA progression after radical prostatectomy. ${ }^{16-18}$ This contention cannot be proved without controlled trials documenting greater survival with aggressive treatment. Another justification is that the higher specificity of PSA in younger men might reduce the number of prostate biopsies. ${ }^{19}$ Unfortunately, the common practice of lowering the PSA biopsy threshold for men in their 40s to increase test sensitivity inevitably reduces specificity. ${ }^{20}$ Finally, the AUA authors assert that obtaining a PSA level at 40 years can establish a baseline for calculating PSA velocity and determining subsequent screening intervals. Analyses of the ERSPC ${ }^{21}$ and the Prostate Cancer Prevention Trial ${ }^{22}$ data, however, show that measuring PSA velocity does not appreciably improve the predictive value of total PSA

These arguments supporting prostate screening at 40 years seem weak in the face of epidemiologic reality, decision modeling, and the evidence from the ERSPC. Tellingly, the American Cancer Society, which has often recommended cancer screening when more conservative guidelines have not, recommends in its most recent screening guidelines holding screening discussions before 50 years only with men in high-risk 
populations (African Americans, positive family history in first-degree relatives). ${ }^{19}$ In May 2012, the USPSTF issued recommendations against screening any healthy man, regardless of age, race, or family history. ${ }^{23}$

\section{DEVELOPING GUIDELINES FOR SCREENING AND PREVENTION RELEVANT TO PRIMARY CARE}

Viewed narrowly, the 2 specialty guidelines appear to be well-meaning efforts that, although based on untested hypotheses rather than direct evidence, might marginally reduce prostate cancer morbidity and mortality. More broadly, however, to propose screening strategies without any direct evidence of benefit takes us in the wrong direction-away from what has been a generally rising standard of evidence-and toward accepting expert opinion as adequate grounds for recommending procedures that expose many to the risk of harms for the benefit of very few.

A direct consequence of following the AUA and NCCN recommendations would be to enlarge the population being counseled about screening. This outcome would reduce the time available for implementing proven screening and preventive services in primary care. Furthermore, when the legal system argues that such guidelines represent the community standard of care, primary care clinicians who fail to follow them may be exposed to unjustified medical-legal action. ${ }^{24}$ Notably, the AUA has been aggressively targeting the media, lawmakers, and patients with proscreening messages after the release of the USPSTF recommendation. ${ }^{25}$

Ideally, groups that develop guidelines will eventually achieve consensus on methodological issues, such as the optimal composition of expert panels, deciding what scientific evidence is strong enough to be admissible, and how to avoid going beyond the evidence when making practice recommendations. To strengthen the guideline development process, generalist clinicians and experts in evidence synthesis should be included on guideline panels and on external review panels. Guidelines should be based on systematic review of the evidence, and not based solely on expert opinion. Widespread use of the Grading of Recommendations, Assessment, Development, and Evaluation (GRADE) system for categorizing the quality of evidence and the strength of recommendations would be an important step in the right direction. ${ }^{26}$ The Institute of Medicine recently issued performance standards for practice guideline developers (Table 1 ), ${ }_{1}^{27}$ and the American Cancer Society has committed to following these principles. ${ }^{28}$

Most primary care clinicians lack the time to study guidelines and form independent opinions about them. In an important trend, primary care professional societies have begun to vet specialty guidelines. The American College of Physicians is developing Clinical Guidance Statements ${ }^{29}$ and the American Academy of Family Physicians ${ }^{30}$ has implemented evidence-based processes for evaluating guidelines developed by other organizations. The publication of rigorous GRADE and Institute of Medicine standards for developing and assessing the credibility of guidelines along with primary care professional society efforts to filter specialty guidelines are encouraging signs. This support will empower clinicians to choose which guidelines belong in primary care practice, enabling them to focus on providing services with proven effectiveness and value to their patients.

To read or post commentaries in response to this article, see it online at http://www.annfammed.org/content/10/6/568.

\begin{tabular}{|c|c|}
\hline Standard & Criteria \\
\hline Establishing transparency & Explicit and publically accessible process \\
\hline $\begin{array}{l}\text { Management of conflict of } \\
\text { interest }\end{array}$ & $\begin{array}{l}\text { Guideline members should disclose all potential conflicts and } \\
\text { divest when necessary } \\
\text { The group should limit the number of members with conflicts }\end{array}$ \\
\hline $\begin{array}{l}\text { Guideline development group } \\
\text { composition }\end{array}$ & $\begin{array}{l}\text { The group should be multidisciplinary and balanced } \\
\text { Patient and public involvement should be facilitated }\end{array}$ \\
\hline $\begin{array}{l}\text { Clinical practice guidelines- } \\
\text { systematic review intersection }\end{array}$ & Use or commission high-quality systematic reviews \\
\hline $\begin{array}{l}\text { Establishing evidence founda- } \\
\text { tions for and rating strength } \\
\text { of recommendations }\end{array}$ & $\begin{array}{l}\text { Explain reasoning for recommendations } \\
\text { Rate the level of confidence and strength of the recommendation }\end{array}$ \\
\hline \multirow[t]{2}{*}{$\begin{array}{l}\text { Articulation of } \\
\text { recommendations }\end{array}$} & $\begin{array}{l}\text { Explicitly detail the recommended action and circumstances for } \\
\text { performing a recommended action }\end{array}$ \\
\hline & $\begin{array}{l}\text { Strong recommendations should be worded to facilitate compli- } \\
\text { ance evaluations }\end{array}$ \\
\hline \multirow[t]{4}{*}{ External review } & $\begin{array}{l}\text { External reviewers should comprise a full spectrum of relevant } \\
\text { stakeholders }\end{array}$ \\
\hline & Reviewers' identities should be kept confidential \\
\hline & Responses to reviewer comments should be recorded \\
\hline & Draft guidelines should be available for public comment \\
\hline \multirow[t]{3}{*}{ Updating } & Regularly monitoring literature \\
\hline & Plan periodic updates \\
\hline & Modify recommendations when important new evidence emerges \\
\hline
\end{tabular}


Key words: prostate-specific antigen; early detection of cancer; guidelines as topic; evidence-based medicine

Submitted August 12, 2011; submitted, revised, January 31, 2012; accepted February 9, 2012.

Funding support: Dr Hoffman is supported by the Department of Veterans Affairs.

\section{References}

1. Early detection of prostate cancer and use of transrectal ultrasound. In: American Urological Association 1992 Policy Statement Book. Baltimore, MD: American Urological Association; 1992.

2. Mettlin C, Jones G, Averette H, Gusberg SB, Murphy GP. Defining and updating the American Cancer Society guidelines for the cancer-related checkup: prostate and endometrial cancers. CA Cancer J Clin. 1993;43(1):42-46.

3. U.S. Preventive Services Task Force. Screening for prostate cancer: recommendation and rationale. Ann Intern Med. 2002;137(11):915-916.

4. American Urological Association. Prostate-specific Antigen Best Practice Statement: 2009 Update. http://www.auanet.org/content/guidelinesand-quality-care/clinical-guidelines/main-reports/psa09.pdf.

5. National Comprehensive Cancer Network. Prostate Cancer Early Detection. 2011 [updated 6/1/11]. http://www.nccn.org/professionals/ physician_gls/pdf/prostate_detection.pdf.

6. Hoffman RM, Couper MP, Zikmund-Fisher BJ, et al. Prostate cancer screening decisions: results from the National Survey of Medical Decisions (DECISIONS study). Arch Intern Med. 2009;169(17): 1611-1618.

7. Guerra CE, Jacobs SE, Holmes JH, Shea JA. Are physicians discussing prostate cancer screening with their patients and why or why not? A pilot study. J Gen Intern Med. 2007;22(7):901-907.

8. Federman DG, Goyal S, Kamina A, Peduzzi P, Concato J. Informed consent for PSA screening: does it happen? Eff Clin Pract. 1999;2(4): 152-157.

9. United States Preventive Services Task Force. USPSTF A and B Recommendations. Washington, DC; Health and Human Services; August 2010. http://www.uspreventiveservicestaskforce.org/uspstf/ uspsabrecs.htm.

10. Yarnall KS, Pollak KI, Østbye T, Krause KM, Michener JL. Primary care: is there enough time for prevention? Am J Public Health. 2003. 93(4):635-641.

11. Andriole GL, Crawford ED, Grubb RL III, et al; PLCO Project Team. Mortality results from a randomized prostate-cancer screening trial. N Engl J Med. 2009;360(13):1310-1319.

12. Schröder FH, Hugosson J, Roobol MJ, et al; ERSPC Investigators. Screening and prostate-cancer mortality in a randomized European study. N Engl J Med. 2009;360(13):1320-1328

13. Lin K, Lipsitz R, Miller T, Janakiraman S; U.S. Preventive Services Task Force. Benefits and harms of prostate-specific antigen screening for prostate cancer: an evidence update for the U.S. Preventive Services Task Force. Ann Intern Med. 2008;149(3):192-199.

14. U.S. Cancer Statistics Working Group. United States Cancer Statistics: 1999-2007 Incidence and Mortality Web-based Report. Atlanta, GA: U.S. Department of Health and Human Services, Centers for Disease Control and Prevention and National Cancer Institute; 2010. http:// apps.nccd.cdc.gov/uscs/cancersbyraceandethnicity.aspx.
15. Howard K, Barratt A, Mann GJ, Patel MI. A model of prostatespecific antigen screening outcomes for low- to high-risk men: information to support informed choices. Arch Intern Med. 2009;169(17): 1603-1610.

16. Carter HB, Epstein JI, Partin AW. Influence of age and prostatespecific antigen on the chance of curable prostate cancer among men with nonpalpable disease. Urology. 1999;53(1):126-130.

17. Khan MA, Han M, Partin AW, Epstein JI, Walsh PC. Long-term cancer control of radical prostatectomy in men younger than 50 years of age: update 2003. Urology. 2003;62(1):86-91, discussion 91-92

18. Smith CV, Bauer JJ, Connelly RR, et al. Prostate cancer in men age 50 years or younger: a review of the Department of Defense Center for Prostate Disease Research multicenter prostate cancer database. J Urol. 2000;164(6):1964-1967.

19. Wolf AM, Wender RC, Etzioni RB, et al; American Cancer Society Prostate Cancer Advisory Committee. American Cancer Society guideline for the early detection of prostate cancer: update 2010. CA Cancer J Clin. 2010;60(2):70-98.

20. Oesterling JE, Jacobsen SJ, Chute CG, et al. Serum prostate-specific antigen in a community-based population of healthy men. Establishment of age-specific reference ranges. JAMA. 1993;270(7): 860-864.

21. Vickers AJ, Wolters T, Savage CJ, et al. Prostate specific antigen velocity does not aid prostate cancer detection in men with prior negative biopsy. J Urol. 2010;184(3):907-912.

22. Vickers AJ, Till C, Tangen CM, Lilja H, Thompson IM. An empirical evaluation of guidelines on prostate-specific antigen velocity in prostate cancer detection. J Natl Cancer Inst. 2011;103(6):462-469.

23. Moyer VA. Screening for prostate cancer: U.S. Preventive Services Task Force recommendation statement. Ann Intern Med. 2012;157(2):120-134.

24. Merenstein D. A piece of my mind. Winners and losers. JAMA. 2004;291(1):15-16.

25. News Center. AUA Speaks Out Against USPSTF Recommendations. Baltimore, MD: American Urological Association; 2011. http://www .auanet.org/content/health-policy/government-relations-andadvocacy/in-the-news/uspstf-psa-recommendations.cfm?acid $=8739$ 296777\%7CNE2UroSTAT666\&W/T.mc id=NetNews6652.

26. Guyatt GH, Oxman AD, Vist GE, et al; GRADE Working Group. GRADE: an emerging consensus on rating quality of evidence and strength of recommendations. BMJ. 2008;336(7650):924-926.

27. Institute of Medicine. Clinical practice guidelines we can trust. National Academy of Sciences; 2011. http://www.iom.edu/ Reports/2011/Clinical-Practice-Guidelines-We-Can-Trust.aspx.

28. Brawley O, Byers T, Chen A, et al. New American Cancer Society process for creating trustworthy cancer screening guidelines. JAMA. 2011;306(22):2495-2499.

29. Qaseem A, Snow V, Owens DK, Shekelle P; Clinical Guidelines Committee of the American College of Physicians. The development of clinical practice guidelines and guidance statements of the American College of Physicians: summary of methods. Ann Intern Med. 2010;153(3):194-199.

30. American Academy of Family Physicians. AAFP-endorsement of evidence-based clinical practice guidelines developed by external organizations. Washington, DC: American Academy of Family Physicians; 2011. http://www.aafp.org/online/en/home/clinical/clinicalrecs/ endorsedguidelines.html. 